\title{
Anterior Uveitis with Posterior Synechia and Iris Atrophy Following Implantation of a Phakic Intraocular Lens
}

This article was published in the following Dove Press journal: International Medical Case Reports Journal

\author{
Mehrdad Mohammadpour' \\ Mehdi Mazloumi (D) ${ }^{2}$ \\ Masoud Khorrami-Nejad (D) ${ }^{1,3}$ \\ 'Eye Research Center, Farabi Eye \\ Hospital, Tehran University of Medical \\ Sciences, Tehran, Iran; ${ }^{2}$ Wills Eye \\ Hospital, Thomas Jefferson University, \\ Philadelphia, PA, USA; ${ }^{3}$ School of \\ Rehabilitation, Shahid Beheshti University \\ of Medical Sciences, Tehran, Iran
}

\begin{abstract}
Purpose: To describe a case with acute postoperative uveitis, posterior synechia and iris atrophy following iris-claw phakic intraocular lens (pIOL) implantation.

Methods: A case report.

Results: A 26-year-old man with high myopia had implantation of a -14.0 diopter, foldable, iris-claw Artiflex (model 401) anterior chamber pIOL (Ophtec B.V.) in both eyes. On the third postoperative day, the patient had significant postoperative inflammation in the left eye and received topical steroids and mydriatic eye drops. On the fifth postoperative day, the right eye had a round pupil and centered pIOL, but the left eye had an atrophic iris and dilated pupil with significant posterior synechias over the inferior half of the pupil. Despite intensive topical steroid application, the synechias remained one year after surgery.

Conclusion: Severe uveitis with posterior synechia can occur after iris-claw pIOL implantation. We hypothesized that excessive iris tissue enclavation in the pIOLs haptics and large iridotomies may be an associated factor.
\end{abstract}

Keywords: phakic intraocular lenses, anterior uveitis, posterior synechia, iris atrophy

\section{Introduction}

Phakic intraocular lenses (pIOLs) revolutionized refractive surgery and currently are an excellent option for high refractive errors not suitable for laser vision correction. ${ }^{1}$ A 6.2-mm corneal incision is essential for the phakic intraocular lens implantation due to the polymethyl-methacrylate (PMMA) material. Therefore, this technique can induce significant postoperative astigmatism. The surgically induced astigmatism (SIA) following iris-claw pIOLs was reduced through the development of the foldable versions (Artiflex, Ophtec BV, Groningen, The Netherlands/Veriflex, Johnson \& Johnson Vision, Santa Ana, CAL, USA). ${ }^{2,3}$ These models of pIOL have PMMA haptics and a $6.0 \mathrm{~mm}$ foldable polysilicon optic and can be implanted through a $3.2 \mathrm{~mm}$ incision. In addition to induced astigmatism, other both early and late complications can occur after implantation of rigid and flexible models of iris-clawtype pIOLs. ${ }^{4-8}$ These complications include uveitis with anterior or posterior synechias, and pigment dispersion possibly related to the contact or closeness of the pIOL with intraocular structures. ${ }^{4,8-14}$, The original model of Artiflex I pIOL (Ophtec, Groningen, The Netherlands) launched in 2004 and then withdrawn from the market, had some of these complications due to presumed too shallow haptic angle but the newer currently available Artiflex pIOL (model 401, Ophtec, Groningen, The
Correspondence: Mehdi Mazloumi Wills Eye Hospital, Thomas Jefferson University, Philadelphia, PA, USA Tel $+\mid 267357786$ |

Email mazloumi.mehdi@gmail.com 
Netherlands) has a new configuration, the step-vaulted haptic in high range powers $(-2.00$ to $-14.50 \mathrm{D})$. $^{4,9-11}$

Herein we describe a case with acute posterior synechia formation implantation in the patient's left eye, following bilateral simultaneous Artiflex pIOL (model 401) foldable silicone iris fixated pIOL.

\section{Case Report}

A 26-year-old man was referred for refractive surgery for high bilateral myopia (-14.0 Diopters) in both eyes. A written informed consent letter has been signed by the patient to allow any case details and any accompanying images published. Based on our hospital policy, Institutional Review Board (IRB) was not required as it was a case report.

The uncorrected distance visual acuity (UCDVA) was 2.00 logMar (Snellen 20/4000) in both eyes; the corrected distance visual acuity (CDVA) was 0.2 logMar (Snellen 20/32) with $-14.00-1.00 \times 180$ in the right eye and 0.3 logMar (Snellen 20/40) with $-14.50-1.25 \times 20$ in the left eye.

The intraocular pressure before surgery was normal $(14.0 \mathrm{~mm} \mathrm{Hg})$ in both eyes. Measurement of ACD between the corneal endothelium and the anterior surface of the crystalline lens, was obtained using the Orbscan II (Bausch \& Lomb, Rochester, NY). In the left eye, anterior chamber depth was $3.41 \mathrm{~mm}$ preoperation and $3.47 \mathrm{~mm}$ after surgery; central corneal thickness before and after surgery was $510 \mu \mathrm{m}$ and $504 \mu \mathrm{m}$, respectively; and photopic pupil size (Orbscan II, Bausch \& Lomb) before and after surgery was $4.35 \mathrm{~mm}$ and $4.38 \mathrm{~mm}$, respectively. Keratometries were 44.1@85 and 42.5@175 in the right eye and 44.7@87/43.1@177 in the left eye. Preoperative corneal endothelial cells density [measured by non-contact specular microscopy (Topcon Corporation, Tokyo, Japan)] was 2533 in the right eye and 2520 in the left eye. Fundoscopy and slit-lamp examination were unremarkable.

The surgical procedure was performed bilaterally under general anesthesia in June 2016 and was uneventful. It started with paracentesis at 10 o'clock and 2 o'clock positions. The ophthalmic viscoelastic device contains sodium hyaluronate $1 \%$ was injected into the anterior chamber (AC). A $3.2 \mathrm{~mm}$ superior limbal tunnel incision was made on the steep meridian, and then -14.0 D Artiflex pIOL implanted to the AC. The Artiflex II pIOL was rotated into the 3 to 9 o'clock position and enclavated in the iris. An iridectomy was done at 12 o'clock in both eyes. The ophthalmic viscoelastic device was irrigated out of the $\mathrm{AC}$ by the main incision, and incisions stromal hydration was performed.

One day after surgery, the Artiflex (model 401) was stable in the appropriate position and iris had normal movement. The UCDVA in both eyes was 0.2 logMar (Snellen 20/32). On the third postoperative day, the patient had significant pain in the left eye and was seen in the eye emergency room at the weekend. The visual acuity was decreased to 0.4 logMar (Snellen 20/50) in the left eye. The intraocular pressure was $14.0 \mathrm{~mm} \mathrm{Hg}$, and on slit-lamp examination, the cornea was clear. However, a significant anterior chamber reaction (4+ cell and flare) was detected and therefore, anterior uveitis was diagnosed. The amount of iris tissue between the iris-claw and the iridectomy size was larger in the left eye. The diagnosis at that time was severe postoperative inflammation in the left eye, and topical steroids and mydriatic eye drops (betamethasone every one hour and tropicamide every six hours) were prescribed for the patient. On the fifth postoperative day, the right eye was quiescent with a wellcentred pIOL (Figure 1). However, the left eye had a dilated atrophic iris and atonic pupil with significant posterior synechias over the inferior half of the pupil and some degrees of ectropion uvea and 3+ anterior chamber cell and flare (Figure 2). The mydriatic eye drop was discontinued. However, after intensive topical steroid application (every one hour on the day after the first postoperative visit and tapered gradually to once a day in two months), the synechias decreased but remained in the inferior part of the pupil in the next visits. Three months after surgery, the patient continued to complain of blurry vision in his left eye with UCVA of $0.5 \operatorname{logMar}$ (Snellen 20/63) and the CDVA, $0.3 \log$ Mar (Snellen 20/40) with+1.00-0.75@180. One year after the operation, the left

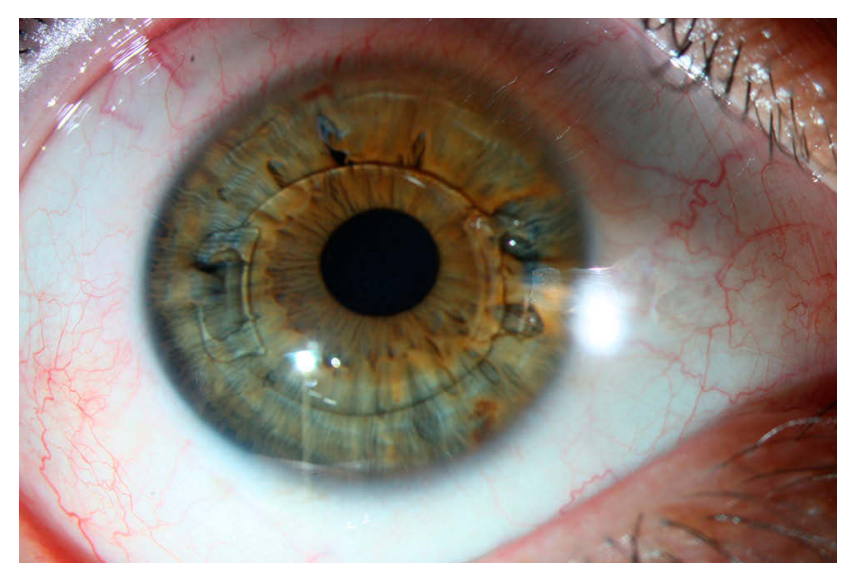

Figure I On the fifth postoperative day, the right eye was calm with a well centered phakic intraocular lens. 


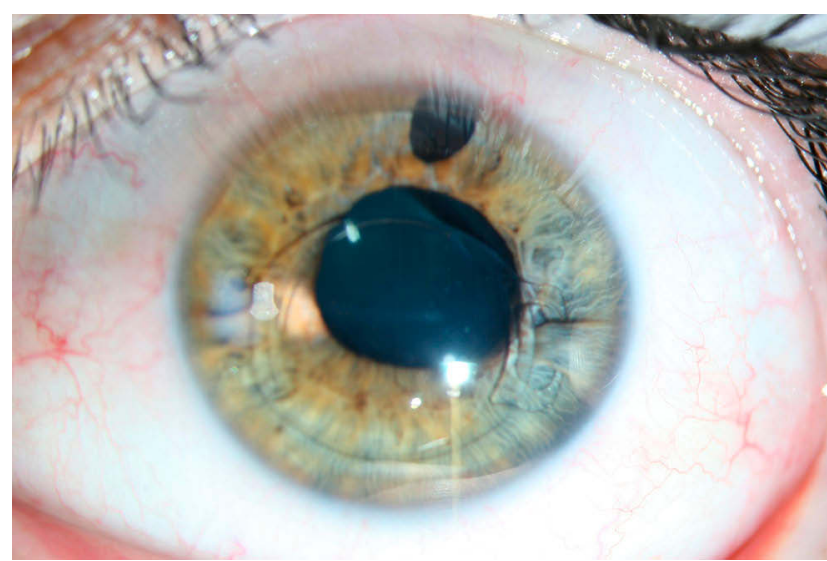

Figure 2 On the fifth postoperative day, the left eye had a dilated atrophic iris and atonic pupil with significant posterior synechias over the inferior half of the pupil and some degrees of ectropion uvea and pigment deposits on the phakic intraocular lens.

eye was quiescent, but the synechia persisted, and the iris was rather atrophic.

\section{Discussion}

Previous studies indicate that Iris-claw pIOLs appear to be an appropriate option for high myopia treatment that could be more effective than laser refractive surgery. ${ }^{1}$ For this surgery, it is mandatory to carefully perform a preoperative assessment of ocular parameters, including $\mathrm{AC}$ depth, iris examination, pupil size, and endothelial cell count (ECC). AC depth is vital in terms of prevention of corneal endothelial cells loss and anterior subcapsular cataract formation. ${ }^{5-7}$ The postoperative inflammatory reactions have been observed in some cases following implantation of $\mathrm{pIOL}$. The $\mathrm{pIOL}$ positioning is essential since a tight enclavation can lead to induce postoperative refractive changes. ${ }^{4,15-17}$

Koss et $\mathrm{al}^{4}$ reported a case with posterior synechias one month after the operation and hypothesized that during surgery, too much iris tissue had been grasped, leading to a too tight enclavation of the iris-claw pIOL. They managed the patient with steroid treatment followed by re-enclavation to halt the progression of synechia progression. In our case, the enclavation was appropriate in the right eye but appeared to be too tight (including too much iris tissue) in the left eye, which in turn seemed to play a significant role in inducing postoperative inflammation and synechia formation. However, given the unsuccessful outcome of re-enclavation to release synechia in Koss et $\mathrm{al}^{4}$ report, the surgeon preferred not to re-enclavate the pIOL. It seems that once the posterior synechia occurred following increased intraocular inflammation, re-enclavation would not subside it and may even exacerbate the intraocular inflammation due to excessive iris tissue manipulation. Another difference between the two eyes of this patient is the much larger iridectomy size in the affected eye, which might cause more inflammation due to increased iris tissue manipulation.

Authors believe that treatment with corticosteroids was an excellent option in stabilizing the situation and reduce the extent of synechia. However, persistent synechia remained even one year after surgery.

We hypothesize that excessive iris tissue enclavation in the pIOLs haptics and large iridotomies may cause more intraocular inflammation and even synechia formation, and we suggest that it is prudent to avoid them during iris-claw pIOL implantation. Mydriatic eye drops should also be avoided in case of postoperative inflammation since it may lead to a persistent dilated pupil and decreased vision if synechia happens. Considering possible longstanding and even permanent vision limiting complications, bilateral pIOL implantation is not encouraged.

\section{Acknowledgment}

The authors would like to thank Mr. Ali Pazoki (Faculty of Science, York University, Toronto, Canada) for his help in editing this article.

\section{Disclosure}

There is no financial interest for the authors in any methods or materials mentioned in this article. The authors report no conflicts of interest in this work.

\section{References}

1. Roberto Pineda II, Chauhan T. Phakic intraocular lenses and their special indications. J Ophthalmic Vis Res. 2016;11(4):422. doi:10.41 03/2008-322X.194140

2. Coullet J, Guëll JL, Fournié P, et al. Iris-supported phakic lenses (rigid vs foldable version) for treating moderately high myopia: randomized paired eye comparison. Am J Ophthalmol. 2006;142(6):909-916. doi:10.1016/j.ajo.2006.07.021

3. Coullet J, Gontran E, Fournié P, Arné JL, Malecaze F. Efficacité réfractive et tolérance de l'implant phaque myopique souple à fixation irienne Artiflex dans la correction chirurgicale de la myopie forte: résultats à deux ans [Refractive efficacy and tolerance of the foldable phakic iris-supported Artiflex lens in the surgical correction of moderately high myopia: a 2-year follow-up]. J Fr Ophtalmol. 2007;30 (4):335-343. doi:10.1016/s0181-5512(07)89603-3

4. Koss MJ, Cichocki M, Kohnen T. Posterior synechias following implantation of a foldable silicone iris-fixated phakic intraocular lens for the correction of myopia. J Cataract Refract Surg. 2007;33 (5):905-909. doi:10.1016/j.jcrs.2006.11.032

5. Galvis V, Villamil JF, Acuña MF, et al. Long-term endothelial cell loss with the iris-claw intraocular phakic lenses $\left(\right.$ Artisan $\left.^{\circledR}\right)$. Graefes Arch Clin Exp Ophthalmol. 2019;257(12):2775-2787. doi:10.1007/s00417019-04506-9 
6. Jonker SMR, Berendschot TTJM, Ronden AE, Saelens IEY, Bauer NJC, Nuijts RMMA. Long-term endothelial cell loss in patients with artisan myopia and artisan toric phakic intraocular lenses: 5- and 10-year results. Ophthalmology. 2018;125 (4):486-494. doi:10.1016/j.ophtha.2017.08.011

7. Jonker SMR, Berendschot TTJM, Ronden AE, Saelens IEY, Bauer NJC, Nuijts RMMA. Five-year endothelial cell loss after implantation with artiflex myopia and artiflex toric phakic intraocular lenses. Am J Ophthalmol. 2018;194:110-119. doi:10.1016/j.ajo.20 18.07 .015

8. Galvis V, Carreño NI, Tello A, Laiton AN. Severe pigment dispersion after iris-claw phakic intraocular lens implantation. Indian J Ophthalmol. 2017;65(12):1492-1494. doi:10.4103/ijo.IJO_743_17

9. Tahzib NG, Eggink FAGJ, Frederik PM, Nuijts RMMA. Recurrent intraocular inflammation after implantation of the Artiflex phakic intraocular lens for the correction of high myopia. J Cataract Refract Surg. 2006;32(8):1388-1391. doi:10.1016/j.jcrs.2006.02.082

10. Güell JL, Manero F. Artiflex (foldable iris claw IOL) secondary implantation for correction of aphakia after penetrating ocular injury [letter]. J Refract Surg. 2004;20(3):282-283. doi:10.3928/1081597X-20040501-16

11. Dick HB, Budo C, Malecaze F, et al. Foldable Artiflex phakic intraocular lens for the correction of myopia: two-year follow-up results of a prospective European multicenter study. Ophthalmology. 2009;116(4):671-677. doi:10.1016/j.ophtha.2008.12.059
12. Sedaghat M, Zarei-Ghanavati M, Ansari-Astaneh MR, Patel V, Sikder S. Evaluation of sterile uveitis after iris-fixated phakic intraocular lens implantation. Middle East Afr J Ophthalmol. 2012;19 (2):199-203. doi:10.4103/0974-9233.95249

13. Messina M, Elalfy M, Fares U, Ghoz N, Mavi B, Dua H. Creeping posterior synechiae following hyperopic iris-fixated phakic implants. Int Ophthalmol. 2016;36(6):901-905. doi:10.1007/s10792-016-0202-y

14. Saxena R, Landesz M, Noordzij B, Luyten GP. Three-year follow-up of the Artisan phakic intraocular lens for hypermetropia. Ophthalmology. 2003;110(7):1391-1395. doi:10.1016/S0161-6420 (03)00405-6

15. Alió J, Mulet M, Gutiérrez R, Galal A. Artisan toric phakic intraocular lens for correction of astigmatism. J Refract Surg. 2005;21 (4):324-331. doi:10.3928/1081-597X-20050701-05

16. Kamiya K, Shimizu K, Kobashi H, et al. Three-year follow-up of posterior chamber toric phakic intraocular lens implantation for the correction of high myopic astigmatism in eyes with keratoconus. $\mathrm{Br}$ J Ophthalmol. 2015;99(2):177-183. doi:10.1136/bjophthalmol-2014305612

17. Kohnen T, Baumeister M, Cichocki M. Intraokularlinsen zur Korrektur von Refraktionsfehlern. Teil I: phake Vorderkammerlinsen [Intraocular lenses for the correction of refraction errors. Part 1: phakic anterior chamber lenses.]. Ophthalmol. 2005;102(10):1003-1007. doi:10.1007/ s00347-005-1271-x

\section{Publish your work in this journal}

The International Medical Case Reports Journal is an international, peer-reviewed open-access journal publishing original case reports from all medical specialties. Previously unpublished medical posters are also accepted relating to any area of clinical or preclinical science. Submissions should not normally exceed 2,000 words or 4 published pages including figures, diagrams and references. The manuscript management system is completely online and includes a very quick and fair peer-review system, which is all easy to use. Visit http://www.dovepress.com/testimonials.php to read real quotes from published authors. 